\title{
Assessment of Nurse's knowledge and practice for patients undergoing Cardiac Catheterization
}

\author{
Olfat F. Thabet ${ }^{1}$, Hala M. Ghanem ${ }^{2}$, Ahmed A. Ahmed ${ }^{3}$ \& Sahar A. Abd-EIMouhsen ${ }^{4}$. \\ 1. Master degree in Adult Nursing Faculty of Nursing, Assiut University, Egypt. \\ 2. Assistant Professor of Medical Surgical Nursing, Faculty of Nursing, Assiut University Egypt. \\ 3. Lecturer of Cardiology, Faculty of Medicine, Assiut University, Egypt. \\ 4. Lecturer of Medical Surgical Nursing, Faculty of Nursing, Assiut University, Egypt.
}

\begin{abstract}
Background: Cardiac catheterization is an invasive procedure indicated in a wide variety of circumstances. It is used for diagnostic evaluation and therapeutic intervention in the management of patients with cardiac diseases. Aim of the study: this study aimed to assess nurse's knowledge and practice regarding patients undergoing cardiac catheterization. Research design: descriptive research design was utilized in this study.Setting: the study was conducted in cardiac catheterization unit at Assiut University Hospital. Participants: A convenience sample including all nurses working (24) at cardiac catheter unit who are willing to participate in the study.Tools: A) Structured interview questionnaire sheet. b) Observation checklist sheet. Results: the results showed that; the highest percent of nurses $(41.7 \%)$ their age was more than 30 years and have diploma degree; $(62.5 \%)$. Their years of experience ranged from5 to 10years $(41.7 \%)$. The majority of nurses $(87.5 \%)$ had no in-service training courses related to cardiac catheterization and heart disease. Conclusion: nurses showed inadequacy of their knowledge and practice regarding care of patients undergoing cardiac catheterization. Recommendations: Nurses are need for inservice training programs and refreshing courses to improve their knowledge which will reflect into their knowledge and practice while working with patients.
\end{abstract}

\section{Key words: Cardiac Catheterization \& Cardiac Diseases.}

\section{Introduction}

Coronary Artery Disease (CAD) has been remaining the first killer and the major cause of public health problems in the world, which is one of the most common causes of morbidity and mortality in different communities. Moreover, CAD is the main cause of death in the United States of America among human adults representing approximately one-third of all deaths, who are over the age of 35years (Hadaegh et al., 2015).

Coronary artery disease affects about 71 millions. About three-quarters of all deaths from cardiovascular disease result from coronary artery disease. In the United States, more than 6 million heart catheterizations are done each year (American Heart Association, 2014). According to cardiac catheterization unit records at the Assiut University Hospital an average of 300 cardiac catheterization cases are admitted monthly as about 3600 case done yearly. Patients after catheterization are transferred to post-catheterization unit then to the general wards.

Cardiac catheterization is an invasive diagnostic and therapeutic procedure indicated in a wide variety of circumstances. It is used for diagnostic evaluation and therapeutic intervention in the management of patients with cardiac diseases (Smeltzer, et al., 2014).

Cardiac catheterization is used to assess coronary artery patency, and to determine the extent of atherosclerosis based on the percentage of artery obstruction. According to the results of coronary angiography either precutaneous coronary intervention (PCI) or coronary bypass surgery (CABG) will be decided (Braunwold, 2014).

The procedure involves insertion of a specialized catheter into the systemic circulation (usually via femoral artery puncture) and advancement into individual coronary arteries or retrograde advancement across the aortic into the left ventricle. In addition, a catheter can be placed through the venous system into the right sided chambers and pulmonary circulation (Suzanne, 2016).

Cardiac catheterization has relatively few contraindications; any correctable illness or condition should be corrected before catheterization to improve safety of the procedure. These conditions include uncontrolled ventricular irritability, uncorrected electrolyte hypokalemia or digitalis toxicity, decompensates congestive heart failure and severe renal insufficiency, active gastrointestinal bleeding, active infection, and severs uncontrolled hypertension (Suzanne, 2016).

Cardiac catheterization is a safe procedure if certain precautions are taken. Although complications are infrequent they do occur and may be life threatening. Complications which occur more frequently include; hemorrhage or occlusion of the artery used for catheter entry, however haematoma

Vol , (7) No, (17) June, 2019 
formation, cardiac arrhythmia and allergic reaction myocardial infarction, vasovagal attack and renal failure from injected dye rarely occur (American Heart Association 2014).

Nursing care for patients undergoing cardiac catheterization requires an expert nurse who understands the types of complications that can occur, as well as the assessment skills to spot them. The combination of nursing knowledge and skills during the period before and after cardiac catheterization aims to assure safe and accurate procedure, and improving physical and mental health (Smeltzer et al., 2014).

Patients' education before cardiac catheterization is very important; the nurse should explain the procedure to the patients. A visit to the catheterization laboratory is also required and patients should watch a video of the procedure. The nurse's role is not only concerned with implementation of patient teaching but also monitoring and caring for the patient post cardiac catheterization to prevent complications (Suzanne, 2016).

\section{Significance of the study}

According to the patients records in catheterization unit at Assiut University Hospital, through 2015. It was round that there were 300 cases cardiac catheterization were admitted in cardiac catheterization unit at Assuit University. Those patients need for special care. Therefore this study will be conducted to asses of nurses' knowledge and practice for patient undergoing cardiac catheterization (Statistical Record of Assiut University Hospital, 2015).

\section{Aim of the Study}

The aim of this study was to assess nurse's knowledge and practice for patients undergoing cardiac catheterization.

\section{Research question}

- What is the level of nurse's knowledge and practice for patient undergoing cardiac catheterization?

\section{Materials \& Method}

\section{Research design}

Descriptive research design was utilized in this study.

The methodologies were divided into four designs:

1- Technical design.

2- Operational design.

3- Administrative design.

4- Statistical design.

\section{Technical design Setting}

The study was conducted in the cardiac catheterization unit at Assiut University Hospital.

Study sample

A sample of all available nurses (24) working in cardiac catheterization unit.

\section{Study tools:}

Data pertinent to the study were collected, utilizing the following three tools:

Tool 1- A structured interview questionnaire sheet for nurses:

Questionnaire sheet was constructed after reviewing the relevant literature to assess nurses' knowledge about nursing care for patient with cardiac catheterization. It was developed and translated into Arabic language.

It was divided into:

- Part I: includes socio- demographic characteristics of the study sample (age, marital status, qualification, years of experiences, and attendances of training programmers.

- Part II: Assess nurse's level of knowledge as regard to: a- Heart and coronary arteries disease.

- Part III: Regard to nursing care for patients undergoing before, during, after cardiac catheterization, structured interview questionnaire sheet, was administered by the researcher to the nurses for answering all its components then collected.

Scoring system: The total score for all items was 84 . Each right answer was given two degrees. Those who obtained less than $70 \%$ were considered having unsatisfactory level of knowledge. While those who obtained from $70 \%$ or more considered having satisfactory level of knowledge.

\section{Tool II-Observation checklist sheet for nurses}

This tool was developed by Researcher based on extensive review of literature for assessing the nurses' practice regard cardiac catheterization. It consists of three parts:

1- Pre- procedures preparations.

- Preoperative nursing care is met individually for each patient.

2- Intra- procedures which include infection control measures such as:

- Principles of aseptic technique.

- Surgical hand washing.

- Applying a sterile glove.

- Wearing mask.

- Wearing gown.

- Nursing care during surgery.

3- Post- procedures:

- Immediate postoperative nursing care for cardiac catheterization patients. 
- Assessing and monitoring vital signs (temperature, pulse and blood pressure).

- Instructing patient on coughing and deep breathing exercise.

- Peripheral venous catheter insertion.

- Patient's instructions before discharge.

Scoring system: Each item was observed, categorized, and scored as follow: two for each step that was done correct (correctly, in time and with the required frequency) and one for each step done incorrect (incorrectly, not in time and without the required frequency) and zero for step that not done. The total score for all items was 480. Those who scored less than $(70 \%)$ were considered having inadequate level, above $(70 \%)$ were considered having adequate level of practice.

\section{Operational design}

Pilot study

A pilot study was implemented on $10 \%$ of the total study subjects to test the tools. Analyses of the pilot study revealed that minimal modifications are required. These modifications were done and the subjects were not excluded in the actual study.

\section{Method}

An official permission to conduct the study was obtained by the researcher from the head of the cardiac catheterization unit at Assiut university hospital. Nurses and patient were formed of the purpose and nature of the study. The investigator emphasized that the participation is voluntary and confidentiality and anonymity of the subjects will be assured through coding all of data.

A structured interview was utilized to fill out the questionnaire sheet (tool 1). Observation technique was utilized to fill out the check list for practice of nurses (tool 2).

\section{Procedure}

The study was carried out on 3 phases:

Phase 1: (Preparatory phase):

A review of current and past, local and international related literature in the various aspects of the problems using books, articles, periodicals, and magazines was done. The proposed study setting was assessed for the number of nurses. This phase ended by a pilot study.

\section{Content validity}

It was established by panel of 5 expertises' who reviewed the instruments for clarity, relevance, comprehensiveness, understanding, applicability and easiness, minor modifications were required.

Phase 2: (Planning phase):

Based on findings of the exploratory phase, the assessment of nurse's knowledge and practice was done.

Phase 3: (Implementation phase):
Data were collected from the cardiac catheterization unit at Assiut University Hospital during one year. The purpose of the study was explained to the nurses prior to answering the questions. The study was carried out at morning, and afternoon shifts.

At initial interview the researcher introduced herself to initiate line of communication, explain the nature and purpose of the study and fill out the structured interview sheet (tool I) to assess nurse's knowledge and the researcher filled out the observation checklist sheet (tool II) to assess nurse's practice for patient undergoing cardiac catheterization.

\section{Administrative design}

Permission to carry out the study was obtained from the responsible hospital authorities of the catheterization unit at Assiut University Hospital, after explaining the aim of the study.

\section{Ethical consideration}

At initial interview, each patient and nurse were informed with the purposes of the study. And the researcher emphasized that the participant is voluntary and confidentiality and anonymity of the subjects will be assured through coding of all data.

\section{Statistical analysis}

Data entry and data analysis were done using SPSS version 19 (Statistical Package for Social Science). Data were presented as number, percentage, mean, standard deviation. Chi-square test was used to compare between qualitative variables. 


\section{Results}

Table (1): Frequency distribution of demographic characteristics of the studied nurses $(n=24)$.

\begin{tabular}{|c|c|c|}
\hline \multirow{2}{*}{ Characteristics } & \multicolumn{2}{|c|}{ Frequency $(n=24)$} \\
\hline & N. & $\%$ \\
\hline \multicolumn{3}{|l|}{ Age: (years) } \\
\hline$\bullet \quad<20$ & 7 & 29.2 \\
\hline - $20-30$ & 7 & 29.2 \\
\hline - $>30$ & 10 & 41.7 \\
\hline Mean \pm SD & \multicolumn{2}{|c|}{$30.29 \pm 7.02$} \\
\hline \multicolumn{3}{|l|}{ Sex: } \\
\hline - Male & 3 & 12.5 \\
\hline - $\quad$ Female & 21 & 87.5 \\
\hline \multicolumn{3}{|l|}{ Marital status: } \\
\hline - $\quad$ Single & 8 & 33.3 \\
\hline - $\quad$ Married & 16 & 66.7 \\
\hline \multicolumn{3}{|l|}{ Level of education: } \\
\hline - $\quad$ Nursing diploma & 15 & 62.5 \\
\hline - Technical institute of nursing & 5 & 20.8 \\
\hline - $\quad$ Baccalaureate degree of nursing & 4 & 16.7 \\
\hline \multicolumn{3}{|l|}{ Years of experience: } \\
\hline$\bullet \quad<3$ & 6 & 25.0 \\
\hline - $3-<5$ & 5 & 20.8 \\
\hline - $\quad 5-<10$ & 10 & 41.7 \\
\hline - $\geq 10$ & 3 & 12.5 \\
\hline Mean \pm SD & $7.18 \pm 4.25$ & \\
\hline \multicolumn{3}{|l|}{$\begin{array}{l}\text { Previously Attended training courses related to cardiac } \\
\text { catheterization and heart diseases: }\end{array}$} \\
\hline - Yes & 3 & 12.5 \\
\hline - $\quad$ No & 21 & 87.5 \\
\hline
\end{tabular}

Table (2): Total mean knowledge scores obtained by nurses working with patients undergoing cardiac catheterization $(n=24)$.

\begin{tabular}{|l|c|c|c|}
\hline \multicolumn{1}{|c|}{ Knowledge items } & Maximum score & Mean \pm SD & Range \\
\hline $\begin{array}{l}\text { Knowledge about anatomy of heart and coronary } \\
\text { artery disease, cardiac catheterization. }\end{array}$ & $\mathbf{3 2}$ & $13.00 \pm 2.70$ & $7.0-19.0$ \\
\hline $\begin{array}{l}\text { Knowledge about nursing care of patients before } \\
\text { cardiac catheterization. }\end{array}$ & $\mathbf{8}$ & $3.08 \pm 1.89$ & $0.0-6.0$ \\
\hline $\begin{array}{l}\text { Knowledge about nursing care of patients during } \\
\text { cardiac catheterization. }\end{array}$ & $\mathbf{1 8}$ & $7.88 \pm 0.90$ & $6.0-10.0$ \\
\hline $\begin{array}{l}\text { Knowledge about nursing care of patients after cardiac } \\
\text { catheterization. }\end{array}$ & $\mathbf{2 6}$ & $9.88 \pm 1.23$ & $7.0-12.0$ \\
\hline Total score of knowledge. & $\mathbf{8 4}$ & $33.83 \pm 4.65$ & $23.0-46.0$ \\
\hline
\end{tabular}

Table (3): level of studied nurses regarding knowledge for patients undergoing cardiac catheterization.

\begin{tabular}{|l|c|c|}
\hline \multicolumn{1}{|c|}{ Level of nurse's knowledge } & \multicolumn{2}{|c|}{ Pre-test (n= 24) } \\
\cline { 2 - 3 } & N. & 87.5 \\
\hline - Unsatisfactory & 21 & 12.5 \\
\hline - Satisfactory & 3 & \\
\hline
\end{tabular}


Table (4): Total mean practice scores obtained by nurses for patients undergoing cardiac catheterization $(n=24)$.

\begin{tabular}{|l|c|c|c|}
\hline \multicolumn{1}{|c|}{ Nurses practice } & Maximum score & Mean \pm SD & Range \\
\hline Efficient pre-operative care. & 38 & $7.13 \pm 2.01$ & $4.0-11.0$ \\
\hline Peripheral venous catheter: & 44 & $9.63 \pm 2.24$ & $3.0-13.0$ \\
\hline Coughing: & 26 & $3.92 \pm 1.38$ & $1.0-7.0$ \\
\hline Ensure continuous monitoring: & 102 & $34.21 \pm 6.31$ & $17.0-45.0$ \\
\hline Infection control measures: & 112 & $31.46 \pm 7.42$ & $11.0-46.0$ \\
\hline Efficient nursing care during surgery: & 32 & $11.42 \pm 4.28$ & $1.0-21.0$ \\
\hline Post-operative criteria: & 36 & $3.21 \pm 1.56$ & $1.0-6.0$ \\
\hline Educating patients before discharge: & 72 & $5.21 \pm 4.96$ & $0.0-18.0$ \\
\hline Ensure the nurses are follow professionalism: & 18 & $4.77 \pm 1.26$ & $0.0-7.0$ \\
\hline Total score of performance: & 480 & $111.97 \pm 17.89$ & $56.0-158.0$ \\
\hline
\end{tabular}

Table (5): Relation between nurse's knowledge and their practice scores nursing for patients undergoing cardiac catheterization.

\begin{tabular}{|c|c|c|c|c|c|}
\hline \multirow{3}{*}{ Knowledge score } & \multicolumn{4}{|c|}{$\begin{array}{c}\text { Practice score } \\
\end{array}$} & \multirow{3}{*}{ P-value } \\
\hline & \multicolumn{2}{|c|}{ Inadequate $(n=4)$} & \multicolumn{2}{|c|}{ Adequate $(n=20)$} & \\
\hline & $\mathbf{N}$. & $\%$ & N. & $\%$ & \\
\hline - Unsatisfactory & 3 & 75.0 & 2 & 10.0 & \multirow{2}{*}{$0.018 * *$} \\
\hline - $\quad$ Satisfactory & 1 & 25.0 & 18 & 90.0 & \\
\hline
\end{tabular}

**High significant

Table(1): Shows that; the highest percent of nurses $(41.7 \%)$ their age was more than 30years and have diploma degree; $(62.5 \%),(66.7 \%)$ of them were married, their years of experience ranged from 5 to 10years $(41.7 \%)$ with mean of $(7.18 \pm 4.25)$ years. The majority of nurses $(87.5 \%)$ had no in-service training courses related to cardiac catheterization and heart disease.

Table (2): Shows that low scores of knowledge about nurses working with patients before cardiac catheterization.

Table(3): Indicates that of nurses (87.5\%) had unsatisfactory level of knowledge about nursing care for patients undergoing cardiac catheterization Table(4): Shows that low score of practice about ensure the nurses are follow professionalism.

Table (5): Shows that; there was a high statistical significant relation between nurse's knowledge and their practice scores nursing for patients undergoing cardiac catheterization $(\mathrm{p}<0.018)$.

\section{Discussion}

Today cardiac catheterization becomes a routine procedure in the hospitals. More than 6 million cardiac catheterizations were performed each year in the United States (American Heart Association 2013, 2014) According to statistical records of cardiac catheterization department at Assiut University Hospital an average of 18000 cardiac catheterization were done in the last ten years
(Statistical Record of Assiut University Hospital, 2015).

The discussion will cover the main result findings as follow:

I.Socio-demographic characteristics of nurses.

The results of the present study showed that the majority of nurses their age was more than 30 years, were female and having a nursing diploma was the highest proportion, nearly half of them, their experience ranged from 5 to 10 years and the majority of them have no in service training courses related to cardiac catheterization.

The previous result is disagree with Marquis \& Huston, (2014) who stated that education and training are two components of staff development that occur after an employees' indoctrination (which refers to planned, guided adjustment of employee to the organization and work environment). The staffs' knowledge level and capabilities are a major factor in determining the number of staff required to carry out unit goals. The better trained and more competent the staff, the fewer staff required, which in turn saves the organization money and raise reproductivity.

II. Nurses knowledge about cardiac catheterization.

As regard nurse's knowledge, the current study showed that, there was unsatisfactory level of nurse's knowledge about anatomy of the heart, coronary arteries. This reflects the lack in their scientific preparation. 
So, we can conclude from the data collected and analysis in the present study that all studied nurses weren't properly prepared prior to their working and /or dealing with cardiac catheterization patients and they got their experience while being there, working and managing the patients in the real life emergency situations.

In this respect, Shell, (1999) \& Change, (2006); mentioned that nurses must be able to expand their knowledge in this area through ongoing education, journal, and seminars. Consequently, teaching programs for nursing staff constitute an important part. These programs are urgently designed to assess nursing staff in developing and enhancing the skills needed to provide high standards of care to their patients.

The results of the present study showed significant difference between level of nurses' knowledge and their practice. This may be attributed to that the majority of nurses were adults, they got their experience while being there, working and managing the patients in the real life emergency situation. In this respect, (World Health Organization, 2012); reported that in order to maintain and improve the quality of patient care, continuous data collection, documentation and analyzing patient information is essential.

The present study showed significant difference between total nurses' knowledge score with their years of experience and attendance of training program about care of patient undergoing cardiac catheterization. Attending training program about care of patient undergoing cardiac catheterization help nurses to gain more knowledge about how to provide safe care and prevent or reduce postoperative complications that may occur.

As well, National Institute for Clinical Excellence, (2012) stated that nurses with many years of experience may require minimum of additional instruction before they are ready to take a patient assignment, nurses working in one clinical specialty may need moderate amount of instructions to acquire through training program.

III.Assessment of nurses' practice for patients undergoing cardiac catheterization:

The results of the present study showed that the total score of nurse's practice were adequate and there was significant difference between nurses' practice and different times of preoperative care which include "preoperative, during surgery, postoperative, and before discharge instructions.

The results showed that some points of preoperative care had inadequate practice and others ignored by nurses.
It was found that majority of nurses didn't do preoperative care such as assessment, patient and family preoperative teaching.

Harold \& Dauerman, (2014) suggested that to provide better patient care, member of preoperative team should work together to prepare patients for the psychological consequence of surgery and preoperative information should be provided to patients at outpatient clinics before admission as this time the patients will be un frighten.

It was found that all nurses didn't do assessment for signs and symptoms of potential complication after cardiac catheterization. This may be due to that all nurses didn't have enough information about it and absence of standard of nursing care related to cardiac catheterization.

Kern, (2015) emphasized on although complications following cardiac catheterization are rare their consequence can be life threatening so prompt recognition and intervention are imperative.

This table reported that each organization and profession must set standards and objectives to guide individuals and practitioners in performing safe and effective care. Also not only must standards exist, but leader and managers also must see that subordinates know and understand the standards and employee must be aware that their performance will be measured in terms of their ability to meet the established standards (Punder, 2015).

Regarding four items of teaching given to patients before discharge that include wound care, signs and symptoms of complications, medication and nutrition. The results showed that only minority of nurses give teaching about wound care and nurses didn't give any instructions regarding complications, medication, and nutrition.

This table stated that, discharge teaching for the patient following cardiac catheterization should include information regarding the signs and symptoms of potential complications, when and how contact to the physician, plus written and verbal information regarding medication, wound care, nutrition, and follow up visits with the physician (Kurtzman, 2014).

The nurse must be sure that the patient demonstrates an understanding of all aspects of home care. And emphasized on the family and significant others should be included in discharge teaching.

\section{Conclusion}

Based on the results of the present study, it can be concluded that care;

- Nurses' knowledge and practice regarding for patients undergoing cardiac catheterization in catheterization unit at Assiut University Hospital were inadequate.

Vol , (7) No , (17) June, 2019 


\section{Recommendations}

Based on the results of the present study, the following is recommended:

\section{For nurses:}

1- Nurses should be encouraged to attend specific meetings as workshops and seminars held for coronary artery disease and cardiac catheterization to be acquainted with the most recent advances and skills in the field.

2- Clinical meeting should be planned periodically in order to present to all nurse's new advances in this field.

3- Periodic monitoring of nurse's knowledge and practice to evaluate the level of nurses working in cardiac catheterization unit.

4- Nurses should be aware of the preoperative identification of patients at high risk for developing complication after catheterization.

\section{For administration}

1- Orientation program for all newly nurses and in services training programmers' for experienced nurses about nursing care for patients undergoing cardiac catheterization.

2- The appropriate equipment and supplies necessary for safe practice must be accessible for all nurses in cardiac catheterization unit

3- Teaching unit should be developed at Assiut University Hospital to provide continuous education for patients undergoing cardiac catheterization.

For further and research

1- Replication of this research on a larger probability sample acquired from different geographical areas in Egypt for generalization.

\section{References}

1. American Heart Association (2013): Women Heart Disease and Stroke Statistics, Available at, http://www.American heart.org / presenter. Html? Identifier $=$ 4787. Accessed Marsh 12. 2013.

2. American Heart Association (2014): American College of Cardiology Cardiac Catheterization and Guidelines for Cardiac Catheterization Laboratories, Circulation 85, 2213-2247.

3. Brounwald E., (2014): Heart Disease: A Textbook of Cardiovascular Medicine, $9^{\text {th }}$ Ed., Philadelphia: W.B. Saunders, pp.382-390.

4. Change, J., (2006): Principles of Microsurgery. Published in the internet By Medicine: http://www.emedicine.com/plastic/topic262.html.

5. Hadaegh F., Harati H., Ghanbarian A., \& Azizil F., (2015): prevalence of coronary heart disease among Tehran adults: Tehran lipid and Glucose Study eastern Mediterranean Health journal, volume 15, No. 1.
6. Harold, L., \& Dauerman (2014): Vascular Closure Devices the second Decade. J. Am. Coll. Cardiol: 50; 1617-1626.

7. Kern, L., (2015); Postoperative arterial fibrillation: new directions in prevention and treatment, J Cardiovasc Nurs 19(2): 103.

8. Kurtzman, E., (2014): The contribution of nursing to high value inpatient care, vol.11 (1), p.36 Available at www.Sagepub.com /content/11/36/full text.

9. Marquis, B., \& Huston, C., (2014): Leadership roles and management functions in nursing: Theory and Application, $5^{\text {th }}$ ed., Philadelphia Lippincott Williams\& Wilkins company, chap.9,pp.232-236.

10. National institute for clinical excellence, (2012): Published in the internet from http://www.nice.org. UK/Clin-guide/clingudmain.html.

11. Pudner Rosemary, (2015): Nursing the Surgical Patient, $4^{\text {th }}$ ed. Chapter 14, care of the patient requiring cardiac interventions and surgery $\mathrm{pp}$. 239-67.

12. Shell, S., (1999): Microvascular tissue transfer. Preoperative nursing consideration. Aorn $\mathbf{J}$; 49(4):1032-6, 1038-40, 1024 -3. Published in the pub med by national Library of Medicine: http://www. NLM. microsurgery.com

13. Smeltzer S., Bare B., Hinkle J., \& Cheever K., (2014): Brunner and Suddarth's Textbook of Medical Surgical Nursing $14^{\text {th }}$ ed. Volume 1, chapter 26, assessment of function, Lippincott Williams and Wilkins, p685.

14. Statistical Record (2015): of Assiut University Hospital Assiut (2015).

15. Suzanne C., Smeltzer (2016): Medical Surgical Nursing, $12^{\text {th }}$ Ed., Copyright by Lippincott Williams and Wilkins, pp. 775-777.

16. World Health Organization, (2012): Fifty-fifth world health assembly Quality of care: patient safety report by the Secretariat Medication A55/13 Provisional agenda item 13.923. 